\title{
Socioeconomic Predictors of Diabetes Mortality in Japan: An Ecological Study Using Municipality-specific Data
}

\author{
Tasuku Okui \\ Medical Information Center, Kyushu University Hospital, Fukuoka, Japan
}

Objectives: The aim of this study was to examine the geographic distribution of diabetes mortality in Japan and identify socioeconomic factors affecting differences in municipality-specific diabetes mortality.

Methods: Diabetes mortality data by year and municipality from 2013 to 2017 were extracted from Japanese Vital Statistics, and the socioeconomic characteristics of municipalities were obtained from government statistics. We calculated the standardized mortality ratio (SMR) of diabetes for each municipality using the empirical Bayes method and represented geographic differences in SMRs in a map of Japan. Multiple linear regression was conducted to identify the socioeconomic factors affecting differences in SMR. Statistically significant socioeconomic factors were further assessed by calculating the relative risk of mortality of quintiles of municipalities classified according to the degree of each socioeconomic factor using Poisson regression analysis.

Results: The geographic distribution of diabetes mortality differed by gender. Of the municipality-specific socioeconomic factors, high rates of single-person households and unemployment and a high number of hospital beds were associated with a high SMR for men. High rates of fatherless households and blue-collar workers were associated with a high SMR for women, while high taxable income per-capita income and total population were associated with low SMR for women. Quintile analysis revealed a complex relationship between taxable income and mortality for women. The mortality risk of quintiles with the highest and lowest taxable per-capita income was significantly lower than that of the middle-income quintile.

Conclusions: Socioeconomic factors of municipalities in Japan were found to affect geographic differences in diabetes mortality.

Key words: Mortality, Vital statistics, Japan, Diabetes, Geographic difference, Socioeconomic factors

\section{INTRODUCTION}

The ongoing increase in the prevalence of diabetes-one of the most common lifestyle-related diseases-is a global phenomenon [1]. In Japan, the estimated number of patients with

Received: April 22, 2021 Accepted: July 29, 2021

Corresponding author: Tasuku Okui

Medical Information Center, Kyushu University Hospital,

3-1-1 Maidashi, Higashi-ku, Fukuoka 812-8582, Japan

E-mail: task10300@gmail.com

This is an Open Access article distributed under the terms of the Creative Commons Attribution Non-Commercial License (https://creativecommons.org/licenses/by$\mathrm{nc} / 4.0 / /$ which permits unrestricted non-commercial use, distribution, and reproduction in any medium, provided the original work is properly cited. diabetes has continued to rise; the Japanese Patient Survey showed that the number of patients with diabetes increased from 2.12 million people in 1999 to 3.29 million people in 2017 [2]. Consequently, national expenses related to diabetes control have continued to increase [3]. The burden of diabetes in Japan includes not only directly-related expenses, however, but also higher incidence rates of cardiovascular diseases or cancer $[4,5]$. As such, diabetes prevention continues to be a major public health initiative in Japan.

Socioeconomic status (SES) is known to affect the prevalence and treatment rate of diabetes [6,7]. Accordingly, studies in Japan have found that a low SES is associated with a high prevalence rate of diabetes [7] and type 2 diabetes complica- 
tions [6]. Internationally, diabetes prevalence and mortality have been shown to vary according to region, with urbanization often being associated with a high prevalence rate of diabetes [8]. In Korea, urban areas have been found to have higher type 2 diabetes prevalence rates than rural ones, particularly among low-income individuals [9]. Urban or metropolitan areas in the United States, however, were found to have lower diabetes prevalence and mortality rates, while rural areas tended to have higher diabetes mortality rates [10-12].

Few studies have focused on differences in diabetes prevalence and mortality according to regional socioeconomic levels in Japan. A previous study compared the age-standardized diabetes mortality rates of prefectures in Japan [13], but it is difficult to identify associations between socioeconomic factors and diabetes mortality using these data since there are only 47 prefectures in Japan. More granular data, such as data by municipality, are needed to investigate these associations. In other countries, major geographic differences in the prevalence and mortality rate of diabetes have been found $[14,15]$. Moreover, socioeconomic predictors affecting differences in diabetes mortality between municipalities have yet to be investigated in Japan. By analyzing associations between diabetes mortality and socioeconomic factors using government statistics, we can infer differences in the burden of diabetes according to socioeconomic level across various municipalities.

Thus, in this study, we identified geographic differences in diabetes mortality in Japan using Vital Statistics data and examined the associations between diabetes mortality and socioeconomic factors for each municipality.

\section{METHODS}

Data on most of the characteristics of municipalities were obtained using Japanese census data. The census is conducted every 5 years in Japan, and the most recent census data that could be obtained at the time of this study were from 2015 . Diabetes mortality at the municipality level can be relatively infrequent in Japan, so we combined 5 years of mortality data from 2013 to 2017 for analysis, as previous studies that used municipality-level mortality data have done $[16,17]$. Japanese Vital Statistics data on diabetes mortality according to year and municipality from 2013 to 2017 were used [18]. Diabetes mortality includes all deaths related to the International Classification of the Diseases (ICD) code E10-E14. Population data from 2013 to 2017 according to gender, year, age, and munici- pality were also obtained from national data published by the Ministry of Internal Affairs and Communications [19]. Age was classified using 5-year increments from 0-4 years old to 75-79 years old, in addition to 1 group of those who were 80 or older.

As possible predictors for analysis, as in previous studies, we collected data on the total population, the number of singleperson households, the number of fatherless households, the marriage rate, the divorce rate, the unemployment rate, the number of blue-collar workers, the number of farmers, the selfemployment rate, financial capability index, taxable per-capita income, the number of clinics, the number of physicians, and the number of hospital beds for each municipality $[17,20]$. Data on marriages and divorces were extracted from Vital Statistics for 2015, and data on the number of single-person households, fatherless households, blue-collar workers, and farmers and the unemployment and self-employment rate were extracted from the 2015 census [21]. In addition, the number of clinics and the number of hospital beds were extracted from the Survey of Medical Institutions in 2015 [21]. The number of clinics and number of hospitals beds were used as measures of medical resources for outpatients and inpatients [21]. In addition, the number of physicians was extracted from the Survey of Physicians, Dentists, and Pharmacists conducted in 2014 [21]. Data on taxable per-capita income were extracted from a survey on the status of municipal taxes from 2015 [21], and data on the financial capability index were extracted from financial index data published by the Ministry of Internal Affairs and Communications in 2015 [22]. The financial capability index is an index of the financial wealth of local public bodies in Japan, and it is calculated by subtracting financial demand from financial income. In addition, nationwide map data of municipalities in Japan were obtained from the digital national land information (administrative district) of the Ministry of Land, Infrastructure, Transport and Tourism in Japan [23].

We calculated the standardized mortality ratio (SMR) of diabetes for each municipality using the empirical Bayes method with DCluster (https://cran.r-project.org/web/packages/DCluster/DCluster.pdf) and data on mortality and the population from 2013 to 2017. The SMR is usually calculated using the empirical Bayes method for regions with small populations [24]. Geographic differences in the SMR of diabetes are shown in a map of Japan (Figure 1). In addition, the Spearman rank correlation coefficient was calculated for the SMRs of men and women, and a statistical test was conducted to investigate whether correlation coefficient was higher than 0 . In addition, 

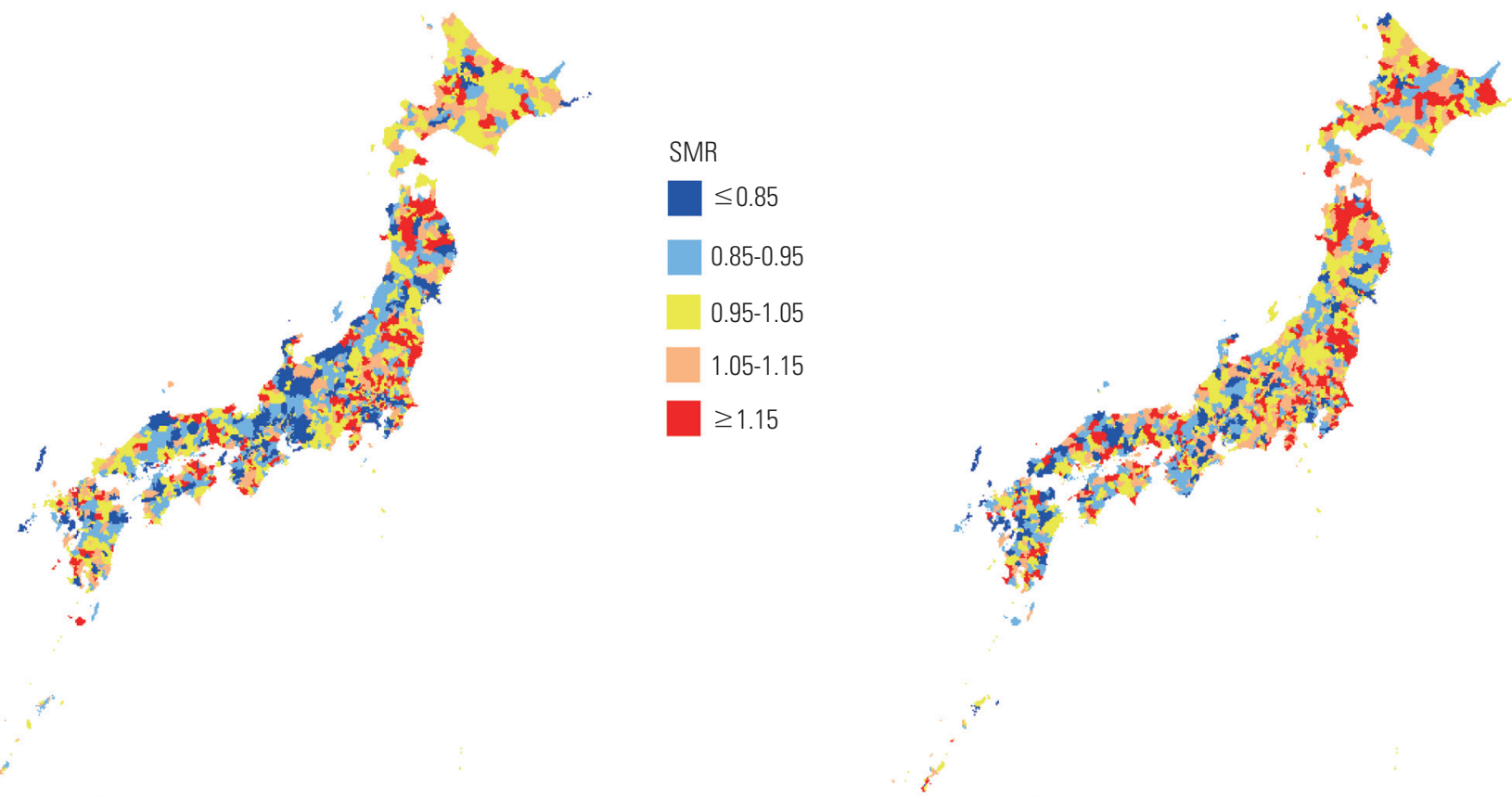

A

Figure 1. Nationwide geographical distribution of the standardized mortality ratio (SMR) of diabetes in municipalities in Japan according to gender (A: men, B: women) from 2013 to 2017.

the Wilcoxon signed rank sum test was used to compare the diabetes mortality rate between men and women. A multiple linear regression model was used to analyze associations between the socioeconomic factors and SMRs of municipalities, and standardized partial regression coefficients and 95\% confidence intervals were calculated for each explanatory variable. By using the identified socioeconomic predictors of diabetes mortality, we classified municipalities into quintiles based on the values of each predictor. Quintiles of municipalities were made for each predictor. Then, the effect of each quintile on diabetes mortality was assessed using Poisson regression analysis, and the relative risks (RRs) of mortality were calculated for the quintiles. We used the actual number of diabetes deaths for each municipality as the outcome and the quintile information as the explanatory variable in Poisson regression analysis. Predicted diabetes mortality for each municipality was used as the offset. All statistical analyses were conducted using R version 3.6.3 (https://www.r-project.org/).

\section{RESULTS}

Figure 1 shows the nationwide geographical distribution of the SMRs of diabetes for men and women in Japanese munici-
Table 1. Basic characteristics of municipalities $(n=1741)$

\begin{tabular}{|c|c|}
\hline Characteristics & Median (interquartile range) \\
\hline Total population & $25234.0(8561.0-65370.0)$ \\
\hline Single-person households ${ }^{1}$ & $276.4(228.7-328.7)$ \\
\hline Fatherless households ${ }^{1}$ & $13.5(10.5-16.7)$ \\
\hline Marriage rate ${ }^{2}$ & $387.4(317.5-467.7)$ \\
\hline Divorce rate ${ }^{2}$ & $157.2(126.3-188.1)$ \\
\hline Unemployment rate ${ }^{3}$ & 39.1 (32.1-46.5) \\
\hline Blue-collar workers ${ }^{3}$ & $73.5(65.5-84.1)$ \\
\hline Farmers $^{3}$ & $70.2(23.9-147.0)$ \\
\hline Self-employment rate ${ }^{3}$ & $159.3(112.1-228.4)$ \\
\hline Financial capability index & $0.44(0.26-0.70)$ \\
\hline Taxable per-capita income ${ }^{4}$ & $1089.3(909.0-1283.0)$ \\
\hline No. of hospital beds ${ }^{2}$ & $1006.1(381.4-1666.8)$ \\
\hline No. of physicians ${ }^{2}$ & $127.6(73.3-191.0)$ \\
\hline No. of clinics ${ }^{2}$ & $68.0(53.9-84.4)$ \\
\hline Diabetes mortality rate of men ${ }^{2}$ & $12.6(8.5-17.4)$ \\
\hline Diabetes mortality rate of women ${ }^{2}$ & $11.0(7.2-16.1)$ \\
\hline
\end{tabular}

${ }^{1}$ Number per 1000 households.

${ }^{2}$ Number per 100000 people.

${ }^{3}$ Number per 1000 people in the labor force.

${ }^{4}$ Unit: 1000 yen.

palities from 2013 to 2017. There were more municipalities with high SMRs for both genders toward the eastern side of 
Japan. The geographical distribution by gender was different, while the Spearman rank correlation coefficient of the SMR for men and the SMR for women was $0.370(p<0.001)$.

Table 1 shows the basic characteristics of municipalities. The diabetes mortality rate in Japan from 2013 to 2017 was higher for men than for women (12.6 and 11.0 deaths, respectively, per 100000 people). The Wilcoxon signed rank sum test used

Table 2. Municipalities with the highest and lowest standardized mortality ratios (SMRs) of diabetes in Japan

\begin{tabular}{|c|c|c|c|c|}
\hline \multirow{2}{*}{$\begin{array}{l}\text { Rank- } \\
\text { ing }\end{array}$} & \multicolumn{2}{|r|}{ Men } & \multicolumn{2}{|r|}{ Women } \\
\hline & SMR & $\begin{array}{l}\text { Municipal name } \\
\text { (Prefecture name) }\end{array}$ & SMR & $\begin{array}{l}\text { Municipal name } \\
\text { (Prefecture name) }\end{array}$ \\
\hline \multicolumn{5}{|l|}{ Top 5} \\
\hline 1 & 1.74 & Misawa city (Aomori) & 1.86 & Muroran city (Hokkaido) \\
\hline 2 & 1.73 & Mishima city (Shizuoka) & 1.65 & Tohoku town (Aomori) \\
\hline 3 & 1.70 & Sennan city (Osaka) & 1.61 & Hachinohe city (Aomori) \\
\hline 4 & 1.69 & Kadoma city (Osaka) & 1.57 & Uruma city (Okinawa) \\
\hline 5 & 1.69 & Takaishi city (Osaka) & 1.56 & Sennan city (Osaka) \\
\hline \multicolumn{5}{|c|}{ Bottom 5} \\
\hline 1 & 0.60 & Yamagata city (Yamagata) & 0.60 & Mino city (Osaka) \\
\hline 2 & 0.61 & Chofu city (Tokyo) & 0.61 & Koganei city (Tokyo) \\
\hline 3 & 0.62 & Toki city (Gifu) & 0.62 & Tajimi city (Gifu) \\
\hline 4 & 0.63 & Kokubunji city (Tokyo) & 0.62 & Matsue city (Shimane) \\
\hline 5 & 0.64 & Fujisawa city (Kanagawa) & 0.63 & Isahaya city (Nagasaki) \\
\hline
\end{tabular}

to compare the mortality rates of men and women showed that the mortality rate was significantly higher for men $(p<0.001)$.

Table 2 shows the municipalities with the highest and lowest SMRs of diabetes in Japan. The municipalities with the highest and lowest SMRs also differed according to gender.

Table 3 shows the results of multiple linear regression analysis. A high number of single-person households, a high unemployment rate, and a high number of hospital beds were significantly associated with a high SMR of diabetes in men. For women, a high rate of fatherless households and blue-collar workers were significantly associated with a high SMR, while high taxable income per-capita income and total population were associated with low SMR for women.

Table 4 shows the RR of diabetes mortality for each quintile of predictors, and the values of predictors for each quintile of municipalities are shown in the Supplemental Material 1. A clear gradient of the RR of diabetes depending on the values for the unemployment rate and the number of hospital beds was observed for men, and a similar trend was observed for women. However, analysis by quintile revealed that the relationship between diabetes mortality and income for women is complex. The mortality risk for both quintile 1 (the lowest-income quintile) and quintile 5 (the highest-income quintile)

Table 3. Results of multiple linear regression analysis

\begin{tabular}{|c|c|c|c|c|}
\hline Characteristics & Men' ${ }^{1}$ & $p$-value & Women $^{2}$ & $p$-value \\
\hline Total population & $-0.022(-0.074,0.029)$ & 0.396 & $-0.060(-0.112,-0.008)$ & 0.024 \\
\hline Single-person households ${ }^{3}$ & $0.103(0.043,0.162)$ & 0.001 & $-0.019(-0.078,0.041)$ & 0.542 \\
\hline Fatherless households ${ }^{3}$ & $0.029(-0.033,0.091)$ & 0.362 & $0.084(0.021,0.146)$ & 0.009 \\
\hline Marriage rate ${ }^{4}$ & $0.049(-0.014,0.113)$ & 0.128 & $-0.021(-0.085,0.043)$ & 0.518 \\
\hline Divorce rate ${ }^{4}$ & $0.044(-0.012,0.100)$ & 0.120 & $0.031(-0.025,0.088)$ & 0.273 \\
\hline Unemployment rate ${ }^{5}$ & $0.139(0.080,0.198)$ & $<0.001$ & $0.047(-0.012,0.106)$ & 0.121 \\
\hline Blue-collar workers ${ }^{5}$ & $0.025(-0.029,0.079)$ & 0.371 & $0.086(0.032,0.141)$ & 0.002 \\
\hline Farmers ${ }^{5}$ & $-0.033(-0.143,0.076)$ & 0.549 & $0.045(-0.064,0.155)$ & 0.417 \\
\hline Self-employment rate ${ }^{5}$ & $0.088(-0.034,0.210)$ & 0.158 & $-0.023(-0.146,0.100)$ & 0.715 \\
\hline Financial capability index & $-0.006(-0.081,0.069)$ & 0.878 & $0.068(-0.007,0.143)$ & 0.077 \\
\hline Taxable per-capita income ${ }^{6}$ & $-0.039(-0.120,0.043)$ & 0.354 & $-0.088(-0.170,-0.006)$ & 0.036 \\
\hline No. of hospital beds ${ }^{4}$ & $0.062(0.007,0.118)$ & 0.029 & $-0.031(-0.087,0.025)$ & 0.275 \\
\hline No. of physicians ${ }^{4}$ & $-0.034(-0.093,0.026)$ & 0.267 & $0.037(-0.023,0.096)$ & 0.232 \\
\hline No. of clinics ${ }^{4}$ & $-0.030(-0.084,0.024)$ & 0.282 & $-0.017(-0.071,0.037)$ & 0.536 \\
\hline
\end{tabular}

Values are presented as standardized partial regression coefficient (95\% confidence interval).

'Multiple R-squared: 0.051; Adjusted R-squared: 0.044; F-statistics: 6.665 ( $p<0.001)$.

${ }^{2}$ Multiple R-squared: 0.041; Adjusted R-squared: 0.034; F-statistics: $5.301(p<0.001)$.

${ }^{3}$ Number per 1000 households.

${ }^{4}$ Number per 100000 people.

${ }^{5}$ Number per 1000 people in the labor force.

${ }^{6}$ Unit: 1000 yen. 
Table 4. Relative risk of diabetes mortality for each quintile ${ }^{1}$ of predictors

\begin{tabular}{|c|c|c|c|c|c|}
\hline Predictors & Quintile 1 (lowest) & Quintile 2 & Quintile 3 & Quintile 4 & Quintile 5 (highest) \\
\hline \multicolumn{6}{|l|}{ Men } \\
\hline Single-person households ${ }^{2}$ & $1.03(0.99,1.08)$ & $1.03(1.00,1.07)$ & 1.00 (reference) & $1.06(1.03,1.10)$ & $1.07(1.04,1.11)$ \\
\hline Unemployment rate ${ }^{3}$ & $0.88(0.84,0.93)$ & $0.93(0.90,0.96)$ & 1.00 (reference) & $1.05(1.02,1.07)$ & $1.12(1.09,1.16)$ \\
\hline No. of hospital beds ${ }^{4}$ & $0.94(0.88,1.00)$ & $0.98(0.95,1.01)$ & 1.00 (reference) & $1.04(1.01,1.07)$ & $1.10(1.07,1.14)$ \\
\hline \multicolumn{6}{|l|}{ Women } \\
\hline Fatherless households² & $0.87(0.83,0.90)$ & $0.94(0.91,0.97)$ & 1.00 (reference) & $1.03(1.00,1.06)$ & $1.04(1.01,1.08)$ \\
\hline Blue-collar workers ${ }^{3}$ & $0.88(0.85,0.91)$ & $0.98(0.95,1.02)$ & 1.00 (reference) & $1.04(1.00,1.08)$ & $1.05(1.00,1.11)$ \\
\hline Taxable per-capita income ${ }^{5}$ & $0.92(0.87,0.98)$ & $0.98(0.94,1.03)$ & 1.00 (reference) & $0.96(0.93,1.00)$ & $0.88(0.85,0.91)$ \\
\hline Total population & $0.98(0.89,1.07)$ & $0.99(0.93,1.06)$ & 1.00 (reference) & $1.00(0.96,1.05)$ & $0.94(0.91,0.98)$ \\
\hline
\end{tabular}

Values are presented as relative risk ( $95 \%$ confidence interval).

${ }^{1}$ Municipalities were classified into quintiles according to each of the predictors, and the municipalities included in each quintile were different depending on the predictors.

${ }^{2}$ Number per 1000 households.

${ }^{3}$ Number per 1000 people in the labor force.

${ }^{4}$ Number per 100000 people.

EUnit: 1000 yen.

was significantly lower than the mortality risk for quintile 3 (the middle-income quintile).

\section{DISCUSSION}

The geographic distribution of diabetes mortality varied by gender. A possible reason for these differences could be that the predictors of diabetes mortality also differed according to gender. Socioeconomic factors, however, affected diabetes mortality for both genders. A possible reason for the association between SES and diabetes mortality may be that healthrelated lifestyles, diabetes prevalence, and diabetes care differ depending on SES. We discuss the possible reasons for the association between diabetes mortality and each predictor hereafter.

An association between single-person households and diabetes mortality was observed in men. According to a previous study in Japan, being unmarried was found to be associated with some negative health behaviors, such as non-attendance of health check-ups or cancer screenings $[25,26]$. In addition, although marital status is known to affect many causes of mortality both in men and women in Japan [27], the RRs of mortality for people who are single compared to people who are married tended to be larger for men than women for many causes of death. Moreover, social support is one of the benefits of marriage [27], and the benefits of marriage may have a more significant effect on men than women. Similarly, being divorced has also been found to have negative effects on some health-related behaviors among women [25], and fatherless households are widely known to be associated with poverty in Japan [28], which may explain the association between fatherless households and diabetes mortality in women. Income and unemployment were also found to be associated with healthrelated behaviors, such as smoking status or dietary habits [25]. Poor dietary habits and smoking have been identified as risk factors for type 2 diabetes in Japan [29,30]. Blue-collar workers were also shown to have an association with poor dietary habits and physical inactivity in Japan [25]. Diabetes is a lifestyle-related disease [29-31], and, as a result, health-related behaviors may have contributed significantly to regional differences in diabetes mortality.

Diabetes prevalence and the utilization of diabetes care also differ according to SES, which is another partial reason for regional differences in diabetes mortality. Blue-collar occupations and coming from a middle-income household were found to be associated with a high prevalence of diabetes mellitus in Japan [7]. Moreover, employment status and income have been found to be associated with certain type 2 diabetes complications in Japan [6]. Differences in the prevalence of diabetes and utilization of diabetes care services according to SES were also found in an international study [32]. In Japan, the utilization of healthcare services and healthcare expenditures of elderly people are known to differ according to income [33], and the treatment rate of diabetes may also differ according to SES. Moreover, according to a previous study from Japan, living alone was found to be significantly associated with outpatient visits 
for endocrine metabolic diseases only for men [34]. One possible explanation for this is that self-management of health and lifestyle may be more difficult for single men than it is for other demographic groups [34].

As shown in Table 4, the lowest quintile of taxable per-capita income also had a relatively low RR for women. One possible explanation for this is that low-income municipalities are not necessarily associated with a higher prevalence of diabetes. Municipalities' taxable per-capita income and total population are known to be positively associated in Japan [35]. Urbanization has also been found to be positively associated with diabetes prevalence and mortality in many countries $[8,9,14]$, with high rates of physical inactivity and high-sugar, high-fat diets being identified as possible factors. Diabetes prevalence may be relatively low in municipalities with a low population level (and a low income level) since the westernization of dietary habits is not as widespread in rural areas in Japan.

Although it is difficult to discern if there is a causal relationship between the number of hospital beds and diabetes mortality, deaths related to diabetes largely occur in hospital beds. Therefore, it is possible that severe diabetes patients are likely to be moved to or be hospitalized in municipalities with large numbers of hospital beds. Alternatively, the number of hospitals bed may tend to increase in municipalities where the hospitalization demand is large.

An association between the prevalence of diabetes by region and SES has also been observed in other countries [15,36], and regions in the United States and Canada with a high percentage of Black or low-income residents have been found to be associated with higher diabetes prevalence and mortality. Regional differences in diabetes mortality have also been observed in China [14], with urbanization, a high mean body mass index (BMI), and a high mean temperature being associated with high diabetes mortality. Factors associated with SES were not examined in a previous study, however, and it is possible that socioeconomic factors may be confounding factors related to the association between diabetes prevalence and mortality and region. In a previous study in the United States, it was found that residents in what is known as the 'Diabetes Belt' tended to be obese and non-Hispanic African American [15]. Two previous studies showed that a high BMI was associated with diabetes prevalence and mortality by region $[14,15]$. Overweight is also associated with a low SES in Japan [37], which may be related to the association between SES and diabetes mortality.

Although SES has been found to relate to diabetes prevalence in Japan [6,7], this study found that differences in socioeconomic factors contributed to differences in diabetes mortality between municipalities. Although it is difficult to resolve socioeconomic differences across municipalities, an intervention to ease the geographical disparity that targets individuals with a low SES should be devised and implemented.

The current study has some limitations worth considering. First, although geographic differences varied depending on the type of diabetes, we were unable to obtain statistical data for each type of diabetes. In addition, unspecified diabetes mellitus (ICD-10 code E14) is the primary cause of diabetes-related death in Japan [18], and statistics on mortality according to the type of diabetes remain unclear. Second, diabetes mortality may not be limited to when the underlying cause of death is diabetes, and data may have included deaths related to cancer or cardiovascular disease that were attributable to diabetes [38]. Moreover, death certificates have been found to underestimate the prevalence of diabetes among decedents in a study in Japan and in another international study $[39,40]$. Further analyses of diabetes-related mortality should be conducted in the future. Third, this is an ecological study, and the results are not necessarily consistent with results obtained from data on individuals. Diabetes is not a major cause of death in Japan, however, and an analysis using individual data would have been difficult for a study focusing on diabetes mortality. Finally, an analysis of the association between the characteristics of municipalities and the current and past SMR of diabetes would have yielded meaningful results indicating the effects of the characteristics of municipalities. However, many small municipalities in Japan have been integrated into larger municipalities, and, from 2000 to 2010, the overall number of municipalities decreased. Therefore, past data on municipalities would be difficult to compare against present-day data.

In conclusion, this study identified the geographic distribution of diabetes mortality in Japan and showed that the distribution was different between men and women. We also identified several factors associated with increased diabetes mortality. High rates of single-person households and unemployment, and high number of hospital beds were significantly associated with high SMRs for men, while high rate of fatherless households and blue-collar workers were significantly associated with high SMRs for women. High-income and total population were significantly associated with an overall decrease in 
the SMR for women only; however, an analysis of income quintiles found that the risk of diabetes mortality in the lowest and highest income quintiles of municipalities was significantly lower than that of the middle-income quintile.

\section{SUPPLEMENTAL MATERIALS}

Supplemental material is available at https://doi.org/10. 3961/jpmph.21.215.

\section{CONFLICT OF INTEREST}

The author has no conflicts of interest associated with the material presented in this paper.

\section{FUNDING}

None.

\section{ACKNOWLEDGEMENTS}

None.

\section{AUTHOR CONTRIBUTIONS}

\author{
All work was done by TO.
}

\section{ORCID}

Tasuku Okui https://orcid.org/0000-0001-5098-8502

\section{REFERENCES}

1. Standl E, Khunti K, Hansen TB, Schnell O. The global epidemics of diabetes in the 21st century: current situation and perspectives. Eur J Prev Cardiol 2019;26(2_suppl):7-14.

2. Ministry of Health, Labour and Welfare of Japan. The patient survey [cited 2021 Apr 17]. Available from: https://www.e-stat. go.jp/stat-search/files?page $=1$ \&toukei $=00450022 \&$ tstat $=$ 000001031167 (Japanese).

3. Urakami T, Kuwabara R, Yoshida K. Economic impact of diabetes in Japan. Curr Diab Rep 2019;19(1):2.

4. Bragg F, Holmes MV, lona A, Guo Y, Du H, Chen Y, et al. Association between diabetes and cause-specific mortality in rural and urban areas of China. JAMA 2017;317(3):280-289.
5. Wojciechowska J, Krajewski W, Bolanowski M, Kręcicki T, Zatoński T. Diabetes and cancer: a review of current knowledge. Exp Clin Endocrinol Diabetes 2016;124(5):263-275.

6. Funakoshi M, Azami Y, Matsumoto H, Ikota A, Ito K, Okimoto H, et al. Socioeconomic status and type 2 diabetes complications among young adult patients in Japan. PLoS One 2017;12(4): e0176087.

7. Hayashino Y, Yamazaki S, Nakayama T, Sokejima S, Fukuhara S. The association between socioeconomic status and prevalence of diabetes mellitus in rural Japan. Arch Environ Occup Health 2010;65(4):224-229.

8. Cheema A, Adeloye D, Sidhu S, Sridhar D, Chan KY. Urbanization and prevalence of type 2 diabetes in Southern Asia: a systematic analysis. J Glob Health 2014;4(1):010404.

9. Lee HY, Won JC, Kang YJ, Yoon SH, Choi EO, Bae JY, et al. Type 2 diabetes in urban and rural districts in Korea: factors associated with prevalence difference. J Korean Med Sci 2010;25(12): 1777-1783.

10. O'Connor A, Wellenius G. Rural-urban disparities in the prevalence of diabetes and coronary heart disease. Public Health 2012;126(10):813-820.

11. Callaghan T, Ferdinand AO, Akinlotan MA, Towne SD Jr, Bolin J. The changing landscape of diabetes mortality in the United States across region and rurality, 1999-2016. J Rural Health 2020;36(3):410-415.

12. Singh GK, Siahpush M. Widening rural-urban disparities in allcause mortality and mortality from major causes of death in the USA, 1969-2009. J Urban Health 2014;91(2):272-292.

13. Sunami S, Okamoto T, Yasunaga K, Ogata M. Geographical study on the mortality from diabetes mellitus: comparison with body weights of pupils. J Okayama Med Assoc 1977;89:51-58 (Japanese).

14. Zhou M, Astell-Burt T, Yin P, Feng X, Page A, Liu Y, et al. Spatiotemporal variation in diabetes mortality in China: multilevel evidence from 2006 and 2012. BMC Public Health 2015;15:633.

15. Barker LE, Kirtland KA, Gregg EW, Geiss LS, Thompson TJ. Geographic distribution of diagnosed diabetes in the U.S.: a diabetes belt. Am J Prev Med 2011;40(4):434-439.

16. Fukuda Y, Nakamura K, Takano T. Cause-specific mortality differences across socioeconomic position of municipalities in Japan, 1973-1977 and 1993-1998: increased importance of injury and suicide in inequality for ages under 75 . Int J Epidemiol 2005;34(1):100-109.

17. Otsubo K, Yamaoka K, Yokoyama T, Takahashi K, Nishikawa M, Tango T. Health care resources and mortality as assessed by 
"the empirical Bayes estimate of standardized mortality ratio": results for municipalities in Japan. Nihon Koshu Eisei Zasshi 2009;56(2):101-110 (Japanese).

18. Ministry of Health, Labour and Welfare of Japan. The vital statistics [cited 2021 Apr 17]. Available from: https://www.e-stat. go.jp/stat-search/files?page $=1$ \&toukei $=00450011$ (Japanese).

19. Ministry of Internal Affairs and Communications. The survey of population, demographics, and household number based on the basic resident register [cited $2021 \mathrm{Apr}$ 17]. Available from: https://www.e-stat.go.jp/stat-search/files?page $=1 \&$ tou kei $=00200241 \&$ tstat $=000001039591$ (Japanese).

20. Okui T. Socioeconomic predictors of trends in cancer mortality among municipalities in Japan, 2010-2019. Asian Pac J Cancer Prev 2021;22(2):499-508.

21. Ministry of Internal Affairs and Communications. General counter for government statistics [cited 2021 Apr 17]. Available from: https://www.e-stat.go.jp/regional-statistics/ssdsview (Japanese).

22. Ministry of Internal Affairs and Communications. Overview of major financial indexes for local public entities [cited 2021 Apr 17]. Available from: https://www.soumu.go.jp/iken/shihyo_ ichiran.html (Japanese).

23. Ministry of Land, Infrastructure, Transport and Tourism. The digital national land information (administrative district) [cited 2021 Aug 20]. Available from: https://nlftp.mlit.go.jp/ksj/ gml/datalist/KsjTmplt-N03-v2_3.html (Japanese).

24. Leyland AH, Davies CA. Empirical Bayes methods for disease mapping. Stat Methods Med Res 2005;14(1):17-34.

25. Fukuda Y, Nakamura K, Takano T. Accumulation of health risk behaviours is associated with lower socioeconomic status and women's urban residence: a multilevel analysis in Japan. BMC Public Health 2005;5:53.

26. Fukuda Y, Nakamura K, Takano T, Nakao H, Imai H. Socioeconomic status and cancer screening in Japanese males: large inequlaity in middle-aged and urban residents. Environ Health Prev Med 2007;12(2):90-96.

27. Ikeda A, Iso H, Toyoshima H, Fujino Y, Mizoue T, Yoshimura T, et al. Marital status and mortality among Japanese men and women: the Japan Collaborative Cohort Study. BMC Public Health 2007;7:73

28. Hayashi Y, Yoda S. An empirical research on the relationship between divorce behavior and social class. Jpn J Res Househ Econ 2014;101:51-62 (Japanese).

29. Akter S, Goto A, Mizoue T. Smoking and the risk of type 2 diabetes in Japan: a systematic review and meta-analysis. J Epi- demiol 2017;27(12):553-561.

30. Morimoto A, Ohno Y, Tatsumi Y, Mizuno S, Watanabe S. Effects of healthy dietary pattern and other lifestyle factors on incidence of diabetes in a rural Japanese population. Asia Pac J Clin Nutr 2012;21(4):601-608.

31. Wise LA, Rosenberg L, Radin RG, Mattox C, Yang EB, Palmer JR, et al. A prospective study of diabetes, lifestyle factors, and glaucoma among African-American women. Ann Epidemiol 2011; 21(6):430-439.

32. Rabi DM, Edwards AL, Southern DA, Svenson LW, Sargious PM, Norton P, et al. Association of socio-economic status with diabetes prevalence and utilization of diabetes care services. BMC Health Serv Res 2006;6:124.

33. Hamada S, Takahashi H, Sakata N, Jeon B, Mori T, lijima K, et al. Household income relationship with health services utilization and healthcare expenditures in people aged 75 years or older in Japan: a population-based study using medical and longterm care insurance claims data. J Epidemiol 2019;29(10):377383.

34. Tsukinoki R, Murakami Y. Association between single-person households and ambulatory treatment of endocrine and metabolic disease in Japan: analysis of the Comprehensive Survey of Living Conditions. Nihon Koshu Eisei Zasshi 2014;61(6):299305 (Japanese).

35. Okui T. Socioeconomic disparities in all-cause and cause-specific mortality rates among municipalities in Japan, 1999-2019. Int J Environ Res Public Health 2020;17(24):9213.

36. Green C, Hoppa RD, Young TK, Blanchard JF. Geographic analysis of diabetes prevalence in an urban area. Soc Sci Med 2003; 57(3):551-560.

37. Nakamura T, Nakamura $Y$, Saitoh $S$, Okamura T, Yanagita M, Yoshita K, et al. Relationship between socioeconomic status and the prevalence of underweight, overweight or obesity in a general Japanese population: NIPPON DATA2010. J Epidemiol 2018;28(Suppl 3):S10-S16.

38. Stokes A, Preston SH. Deaths attributable to diabetes in the United States: comparison of data sources and estimation approaches. PLoS One 2017;12(1):e0170219.

39. McEwen LN, Kim C, Haan M, Ghosh D, Lantz PM, Mangione $\mathrm{CM}$, et al. Diabetes reporting as a cause of death: results from the Translating Research Into Action for Diabetes (TRIAD) study. Diabetes Care 2006;29(2):247-253.

40. Sasaki A, Horiuchi N, Hasegawa K, Uehara M. Studies on proportion of death certificates mentioning diabetes in diabetic patients. J Jpn Diabetes Soc 1991;34:213-218 (Japanese). 